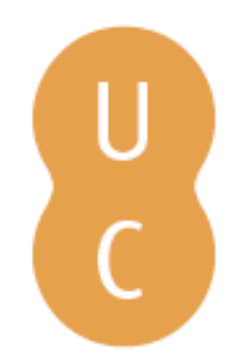

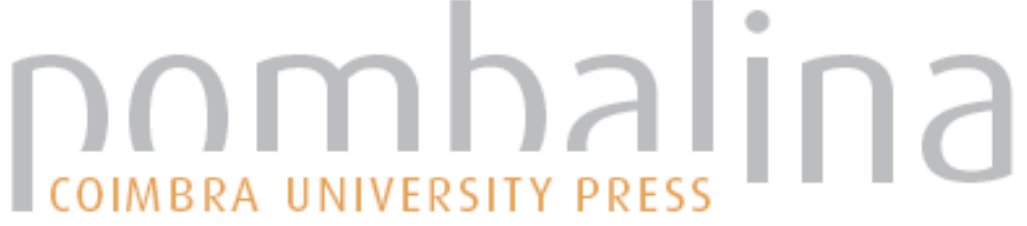

\section{Los humanistas del siglo XV ante los neologismos}

Autor(es): $\quad$ Morcillo León, Abel

Publicado por: Imprensa da Universidade de Coimbra

URL

persistente: URI:http://hdl.handle.net/10316.2/38954

DOI: $\quad$ DOI:http://dx.doi.org/10.14195/978-989-26-0395-7_8

Accessed : $\quad$ 26-Apr-2023 04:26:25

A navegação consulta e descarregamento dos títulos inseridos nas Bibliotecas Digitais UC Digitalis, UC Pombalina e UC Impactum, pressupõem a aceitação plena e sem reservas dos Termos e Condições de Uso destas Bibliotecas Digitais, disponíveis em https://digitalis.uc.pt/pt-pt/termos.

Conforme exposto nos referidos Termos e Condições de Uso, o descarregamento de títulos de acesso restrito requer uma licença válida de autorização devendo o utilizador aceder ao(s) documento(s) a partir de um endereço de IP da instituição detentora da supramencionada licença.

Ao utilizador é apenas permitido o descarregamento para uso pessoal, pelo que o emprego do(s) título(s) descarregado(s) para outro fim, designadamente comercial, carece de autorização do respetivo autor ou editor da obra.

Na medida em que todas as obras da UC Digitalis se encontram protegidas pelo Código do Direito de Autor e Direitos Conexos e demais legislação aplicável, toda a cópia, parcial ou total, deste documento, nos casos em que é legalmente admitida, deverá conter ou fazer-se acompanhar por este aviso.

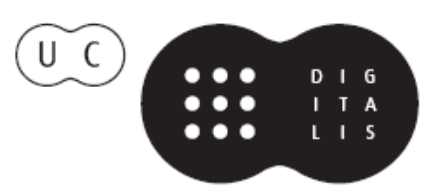


Nair de Nazaré Castro Soares

Santiago López Moreda

Coordenação

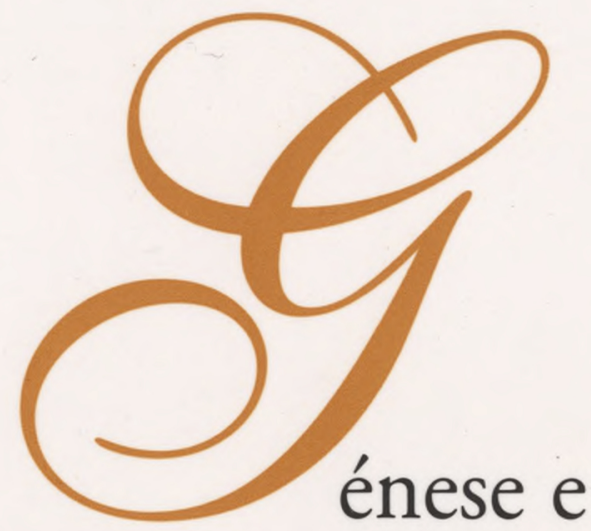

Consolidação da Ideia de Europa

Vol. IV

Idade Média e Renascimento

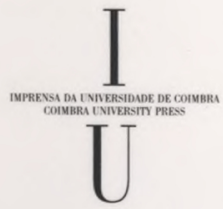

- COIMBra 2009 


\title{
LOS HUMANISTAS DEL SIGLO XV ANTE LOS NEOLOGISMOS
}

\author{
ABEL MORCILLO LEÓN ${ }^{1}$ \\ (Universidad de Extremadura)
}

\section{INTRODUCCIÓN.}

En 1885, el profesor Remigio Sabbadini publicó un libro titulado Storia del Ciceronianismo e di altre questioni letterarie nell'età della Rinascenza. En él, además de la cuestión del Ciceronianismo que aparece ya reflejada en el título mismo, se ocupaba, de manera más breve pero no por ello menos importante, de otros temas de interés y confrontación entre los humanistas italianos. Uno de ellos era el problema de la acuñación de nuevos vocablos latinos: "Sul conair nuovi vocabuli latini", ${ }^{2}$. Según él, ni Petrarca ni los primeros humanistas estuvieron exentos de usar en sus escritos neologismos y barbarismos, ni tampoco sus sucesores, aunque se hubiesen propuesto restaurar la verdadera lengua latina, el latín clásico y puro, y luchar contra lo que se conoce como la barbarie medieval. Ciertamente, desde la Antigüedad, el empleo de neologismos no suscitó grandes problemas ni rudos enfrentamientos ni muchas reflexiones al respecto. Por lo general, se siguió la norma de que, cuando era necesario, se acuñaban nuevos vocablos ${ }^{3}$.

En las líneas que siguen pretendemos trazar un somero bosquejo sobre la postura de los humanistas del siglo XV ante la cuestión de los nova verba ${ }^{4}$,

\footnotetext{
' Investigador en Formación FPU del Ministerio de Educación y Ciencia. Queremos agradecer al Dr. S. López Moreda sus correcciones y consejos, así como al Dr. Villalba Álvarez.

${ }^{2}$ R. SABADDINI, Storia del Ciceronianismo e di altre questioni letterarie nell 'età della Rinascenza, Torino, E. Loescher, 1885, pp. 75-80.

${ }^{3}$ Cf. A. PennacinI, La funzione dell'arcaismo e del neologismo nelle teorie della prosa da Cornificio a Frontone, Torino, Giappichelli editore, 1974.

${ }^{4}$ Bajo este concepto se incluyen todos los tipos de neologismos que define la lingüística moderna: tanto los neologismos de forma como los neologismos semánticos o de sen-
} 
prestando especial atención a la obra histórica de dos importantes figuras del humanișmo europeo: el italiano Lorenzo Valla y el español Elio Antonio de Nebrija.

\section{LA CUESTIÓN DE LOS NOVA VERBA.}

El movimiento humanista, debido a su acusada tendencia a discutir y reflexionar sobre todos los temas que tuvieran alguna relación con la lengua latina, en su intento de depurarla de toda la degeneración medieval para poder alcanzar el auténtico y verdadero latín clásico, no consideró el tema de los nova verba una cuestión baladí, sino que fueron muchos los humanistas que se ocuparon de esta cuestión e intentaron darle una solución adecuada de acuerdo con sus criterios e ideas. Cierto es que muchos utilizaron con frecuencia neologismos sin llegar a hacer un planteamiento teórico sobre ellos. De hecho, no hay ninguna obra dedicada exclusivamente a la cuestión ni tampoco es un tema recurrente en las gramáticas, pero con frecuencia encontramos referencias a los nova verba dispersas en los escritos de los humanistas y no sólo en obras donde esta cuestión tiene su mejor sede, o mejor dicho su sede lógica, es decir, en las de carácter gramatical y lingüístico, sino también en otro tipo de composiciones como epístolas, obras históricas y en un género que los humanistas cultivaron con gusto y pillería: la invectiva.

En su estudio, Sabbadini ${ }^{5}$ establecía que las posturas posibles ante esta cuestión, eran - como casi siempre - tres:

a) los que admiten que se pueden acuñar nuevos vocablos;

b) los que niegan en redondo que puedan acuñarse nuevos vocablos;

c) los conciliadores, que intentando poner de acuerdo las dos posturas extremas, sólo admiten la creación de nuevos vocablos para designar las nuevas ideas o realidades y rechazan aquellos vocablos que designan ideas o realidades antiguas con nombres nuevos.

Esta división tiene para Sabbadini una razón histórica que se ajusta a los dos principales períodos del humanismo, aunque, desde nuestro punto de vista, más que cronológicas, se trata de razones conceptuales, dado que las posturas conviven en el tiempo y dependen, sobre todo, de la idea que tengan los dis-

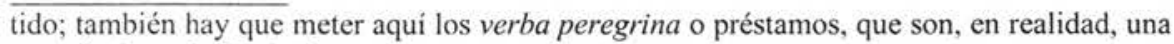
especie de neología de forma.

${ }^{5}$ Op. cit. 
tintos humanistas sobre la lengua latina, si bien es verdad que el período de originalidad tuvo mayor fuerza durante el Quattrocento:

1.- El período de originalidad, que llega hasta la mitad del Quattrocento. Durante esta etapa los humanistas tuvieron necesidad de crear nuevos términos porque pretendian hacer del latín una lengua viva con la que pudieran comunicarse y utilizar en todos los ámbitos: la correspondencia, la escuela, la conversación, sus escritos literarios, etc. Esto suponía que, si el latín era una lengua viva, debía adaptarse al uso y a los modos contemporáneos y a la nueva realidad extralingüistica en la que vivían y se relacionaban. Estos autores despreciaban el vernáculo, que lo habían aprendido desde niños y que era la lengua del pueblo, aunque eran conscientes de que su influencia se dejaba sentir en ese latín "puro" que ellos pensaban hablar.

2.- El período de imitación. En esta segunda etapa, el latín ya no es sentido como una lengua viva, aunque sigue considerándose la lengua más perfecta, que hay conocer para poder leer, comprender e interpretar los textos de los autores clásicos latinos, que son igualmente los más perfectos. Tratando de conseguir esta perfección, se busca también el mejor modelo al que imitar y éste no es otro que Cicerón. La predilección por Cicerón fue casi obsesiva, hasta el punto de que los llamados ciceronianos no admitieron en sus escritos ningún vocablo a no ser que Cicerón lo hubiese utilizado. De ahí su rechazo total y absoluto a las nuevas creaciones léxicas, tan bárbaras o más que todos aquellos barbarismos e incorrecciones medievales que los humanistas tanto criticaban y rechazaban.

Sin duda, el problema de acuñar nuevos términos no era nuevo. Los propios latinos se habian mostrado muy reticentes a las nuevas creaciones léxicas, aunque fueron muchos los que defendieron su necesidad ${ }^{6}$. Pero en el Renacimiento, su importancia se acentuó más aún, si cabe, dado que la bandera que habían enarbolado los humanistas era la de recuperar la auténtica lengua latina y depurarla de todas sus imperfecciones, vicios e impurezas medievales. Y a toda esta barbarie medieval se unía el peso, cada vez mayor, de las lenguas ver-

${ }^{6}$ Cf. Pennacini, Op cit. V. Viparelli Santangelo, "La teoria del neologismo in Orazio" en Bolletino di Studi Latini, 1894, n 14, pp. 39-63. S. Consolı, Il neologismo negli scritti di Plinio, il giovane. Contributo agli studi sulla latinità argentea, Palermo - Catania, Tip. Edit. Barbagallo e Scuderi, 1900. 
náculas, que no se limitaban sólo a ejercer su absoluta primacía en el populus o el vulgus, parcelas que controlaban desde hacía siglos, sino que iban aumentando su importancia y su presencia entre las demás clases sociales y en ámbitos propiamente latinos hasta entonces, como las letras, la administración o la enseñanza.

Por todo ello, intentar que el latín fuese una lengua viva y a la vez clásica chocó de frente con la realidad. Tras más de una quincena de siglos, el mundo había cambiado bastante y recuperar el latín de Cicerón, para muchos el mejor y más elegante de todos, no era suficiente para asegurar el triunfo del latín, pues expresarse brillantemente no significaba lograr el principio fundamental de toda lengua: servir para que dos personas se comuniquen. En este momento, casi todo era diferente: los países, las instituciones políticas y administrativas, las relaciones sociales, la religión, la forma de vivir, etc., y la lengua debía adaptarse a esta nueva situación; máxime cuando la competencia entre el latín y las lenguas romances era tan dura. Sin embargo, no todos los autores lo vieron así, sino más bien al contrario, y la preferencia por el clasicismo a ultranza, por la rigidez extrema y por el férreo conservadurismo de los modelos clásicos, en lugar de por la viveza y agilidad de una lengua natural que se adaptase y acomodase a los nuevos tiempos, hizo más por la ruina de la lengua latina que por su pretendida recuperación. Y, así, el humanismo, nacido para defender y resucitar el latín, entonó, en realidad, su canto de cisne. El latín dejó de ser esa moneda de uso corrienteen palabras de Quintiliano -, para quedar fuera de circulación, aunque mantuviera por siempre su enorme valor innato y alcanzase el valor de una pieza de museo, sin duda, la obra estrella de la colección en el museo de las lenguas.

\section{HISTORIOGRAFIA HUMANISTICA Y NEOLOGISMOS.}

Pues bien, en uno de los ámbitos literarios donde suscitó más polémicas y complejidades la presencia de nova verba fue en la historiografia humanística. Fueron muchos los humanistas que recibieron por parte de los mecenas de turno o de los monarcas bajo cuya protección y manutención estaban el encargo de componer una narración de sus res gestae. Así, al tener que escribir una historia contemporánea, se enfrentaron con el problema de nominar objetos, armas, artefactos, inventos, instituciones, dignidades, cargos, regiones y ciudades, conceptos e ideas, etc., propios de su tiempo, que obviamente eran desconocidos para los antiguos. Todas estas nuevas realidades carecían de nombres específicamente latinos, aunque normalmente sí tenían ya uno asignado por la lengua vernácula en la que habían surgido o en la que se utilizaban. Incluso muchas de estas denominaciones eran antiguas palabras latinas, que 
romanizadas, habían pasado a tener significados diferentes y a designar realidades extralingüísticas distintas, que ahora había que volver a latinizar.

A este respecto, Paul van Tieghem ${ }^{7}$ señala que para nombrar en latín tantos objetos, armas, costumbres e instituciones desconocidas de los antiguos, los prosistas, y sobre todo los historiadores, cuentan con dos procedimientos. Unos, obstinadamente fieles a la historiografia clásica, sobre todo a Livio, buscan equivalentes en el latín clásico mediante perífrasis o rodeos difíciles de entender para un lector moderno, aunque los contemporáneos sí pudieran hacerlo. Otros, por el contrario, preferían la precisión y la exactitud, eran partidarios de forjar términos nuevos o 'latinizar' los términos modernos, aun a costa de cierto tufillo a 'latín de cocina'. En efecto, la historiografia humanística se movió entre estas dos tendencias opuestas: la circuitio verborum frente a los nova verba, entre puristas ciceronianos y 'renovadores'.

\section{LORENZO VALLA E ITALIA.}

En Italia, PetrarCA, situado en el inicio del movimiento humanista, empleó en sus obras históricas términos latinos clásicos "como expresiones corrientes, como si el sentido no hubiera cambiado después y como si sus contemporáneos supieran lo que era un cónsul o un tribuno de la plebe". Similar es la actitud de los puristas posteriores al intentar designar cosas modernas con nombres antiguos, por lo general mediante forzadas equivalencias. Esta costumbre arraigó con fuerza en el humanismo y cercenó, en parte, el rigor histórico.

Básicamente en esta línea esbozada por Petrarca, se mantiene LEONARDO BRUNI, cuya Historia Florentina es, cronológicamente hablando, la primera gran obra de toda la historiografia humanista propiamente dicha. Por lo general, utilizó expresiones clásicas para designar las realidades sobre las que escribía y sólo en ocasiones hizo concesiones al uso contemporáneo ${ }^{9}$.

LORENZO VALLA, por su parte, fue uno de los primeros en alzar su voz en favor de los nova verba ${ }^{10}$, iniciando un camino que después continuaron otros

\footnotetext{
${ }^{7}$ P. VAN TIEGHEM, La Littérature latine de la Renaissance. Étude d' histoire littéraire européenne, Genève, 1966, p. 225.

${ }^{8}$ E. FUETER, Historia de la Historiografia Moderna (2 Volúmenes), Buenos Aires, Ed. Nova, 1953, vol. I, p. 18.

${ }^{9}$ Cf. Fueter, Op. cit., vol. I, pp. 30-35.

${ }^{10}$ Cf. O. BesomI, "Dai Gesta Ferdinandi Regis Aragonum del Valla al De
} 
humanistas como Nebrija, Erasmo o Vives" ${ }^{11}$. Valla mostró siempre hacia ellos una postura de aprobación y aceptación en coherencia lingüística con su posición en las Elegantie, donde una de sus principales preocupaciones es conseguir que cada término sea proprius, peculiaris, aptus y significativus ${ }^{12}$. Desde la perspectiva de Valla, el novum verbum se ajusta perfectamente a estas características y al concepto de "elegantia" por él trazado, dado que contribuye a dotar al texto de perspicuitas y al perfeccionamiento de la latinitas ${ }^{13}$.

En efecto, bajo el lema: nova res novum vocabulum flagitat ${ }^{14}$, Valla defiende el empleo de los nova verba que el usus considere necesarios y justificados: Quare quis non videt rebus nobis esse accommodata nova nomina, ut veteres, a quibus precepta habemus et exempla sumimus, factitarunt? (VALLA, GF 63: I 14.7), afirmando así que no hace otra cosa que seguir los preceptos, normas y ejemplos de los auctores antiguos. Con todo, si bien es verdad que en sus obras L. Valla no teoriza de manera explícita sobre la materia, una serie de indicaciones, repartidas por el Antidotum in Facium y los Gesta Ferdinandi regis Aragonum ${ }^{15}$, nos proporcionan su posición general sobre el tema:

- Toda nueva realidad debe tener un nombre nuevo y propio: At nova res novum vocabulum flagitat. (VALLA, AF 106: I 14.19). Este término debe ser significativus y proprius, de manera que se evite la competencia sinonímica y la ambigüedad. (Cf. VAlLA, $G F$ 195: Appendice III 3; $A F$ 106: I 14.19).

Orthographia del Tortelli" en IMU, N ${ }^{\circ}$ IX, 1966, pp. 75-121.

11 Actitud que también fue duramente criticada por algunos de sus contemporáneos como Bartolomeo Facio, Antonio Becadelli, alias el Panormita, (Cf. B. FAClO, Invective in Laurentium Vallam, E. I. RAO (ed), Napoli, Societa editrice napoletana, 1978) o Poggio Bracciolini en sus Invectivae (Cf. P. BRACCIOLINI, Opera omnia, R FUBINI (ed.), 2 vol., Torino, 1966).

${ }^{12}$ Cf. L. VALLA, Laurentii Vallensis De linguae latinae elegantia, S. LÓPEZ MOREDA (ed.), Cáceres, 1999, pp. 33 y ss.

${ }^{13}$ Cf. S. López Moreda, La "elegantia" en la lengua latina, Madrid, 2006, p. 92 y ss.

${ }^{14}$ Cf. L. VAl.la, Antidotum in Facium, M. Regoliosi (ed.), Padua, 1981, p. XXXV y ss, 14 (I 3.1-3). En adelante: VALLA, $A F$ seguido del número de página de la edición y después libro, capitulo y parágrafo. Cf. también S. LÓPEZ MOREDA (e. p.), "At nova res novum vocabulum flagitat. Neologismos y nuevas acepciones en la prosa latina de los humanistas".

${ }^{15}$ Seguimos la edición de L. VAlla, Gesta Ferdinandi regis Aragonum, O. BESOMI (ed.), Padua, 1973 (en adelante, VALLA, $G F$ ), junto con su traducción al español: L. VALLA, Historia de Fernando de Aragón, S. LóPEz MOREDA (ed.), Madrid, 2002. De especial relevancia con respecto a la cuestión de los neologismos es el breve texto editado por O. Besomi como Appendice III, sobre el que estamos trabajando actualmente, y que pudiera ser parte del "libellus de novis rebus antiquitati prorsus ignotis", que Valla nombre en el $A F 107$ (I $14,23)$. 
- Los encargados de acuñar estas nuevas palabras han de ser los docti: Et certe necesse est ut docti aliquando consituant quibus vocabulis appellande sint ee res que non ita multo superioribus temporibus sunt excogitate. (VALLA, GF 194: Appendice III 1).

- Sólo cuando no haya ningún autor consagrado al que seguir y no exista ninguna referencia escrita de la nueva realidad, Valla propone emplear la denominación vulgar o incluso la vernácula si se trata de un término ya difundido en el usus: magis accedam prius impositis ipso vulgo auctore contentus, quoniam que sequar scriptorem non habeo. (VALLA, GF 199: Appendice III 14).

- Predilección por el término más generalizado y difundido en la consuetudo vigente, cuando existan varias posibilidades, porque la intención última de Valla es poder llegar a ser comprendido por todos los lectores de su tiempo y porque, en materia lingüistica, Valla tiene claro que el usus está por encima de la norma y de la auctoritas $^{16}$. En consecuencia, señala que: inter pares auctoritates plus viris habet plurium usus (VALLA, GF 197: Appendice III 6) ${ }^{17}$. Esto implica también que los términos pueden cambiar de significado con el paso del tiempo y que aparezcan nuevas denominaciones, más precisas y convenientes, para algunos significantes ${ }^{18}$.

En conclusión, dentro del sistema lingüístico latino vivo e histórico concebido por Valla, en el que la elegantia es la guía del usus actual y de la consuetudo vigente, el neologismo no es un mero elemento "funcional" que cubra únicamente la necesidad de expresar las nuevas realidades, no sólo sirve para rellenar este hueco dentro del sistema lingüístico ni es un elemento inventado artificialmente para encajarlo en una frase por obra de un ejercicio de ingenio y casi malabarismo lingüístico, sino un elemento indispensable en el funcionamiento de una lengua latina para solventar necesidades comunicativas, un síntoma claro de su viveza y uno de los principales motores del desarrollo diacrónico de la lengua latina desde la óptica valliana. Así pues, el neologismo es un importante elemento que actualiza la lengua y le da una vigencia contemporánea necesaria para su perfecto desarrollo y que contribuye a generar un continuum entre Antigüedad y Contemporaneidad, entre pasado y presente, con las exclusiones propias de latín medieval que hace Valla, que hacen que la línea de evolución diacrónica del latín sea, en su paso por el latín medieval, en algunos momentos intermitentes o discontinua, pero que nunca se interrumpa o corte del todo.

Flavio Biondo, contemporáneo de Valla, afirma, en cambio, en una obra histórica, que compuso poco después de los Gesta vallianos, que son

${ }^{16}$ Cf. S. LÓPEZ MOREdA, "Norma y usus en las Elegantiae de L. Valla: un intento de sistematización del léxico" en E. SÁnchez Salor, L. Merino Jeréz \& S. López Moreda (eds.), La recepción de las artes clásicas en el siglo XVI, Cáceres, 1996, pp. 111-124.

${ }^{17}$ Este principio también lo deja claro a propósito de los topónimos: VALLA, GF 10 (I 2.1); $A F 151$ (II 4.10).

${ }^{18}$ Cf. Valla, $A F 95$ (I 12.2). 
muchas las dificultades que encuentran sus contemporáneos a la hora de escribir historia, a causa del cambio de significado acontecido en muchos términos clásicos, ideoque qui priscis scriptoribus in promptu et tanquam ex quotidiano loquendi usu facillimi erant, modos dicendi a nobis magna ex parte servari non expediat: quum tamen ab illis, si elegantiae erit inserviendum, usquequaque discedere non liceat ${ }^{19}$. Y, como Valla, no vaciló en emplear 'bombarda' o 'capitani generales' en sus Historiae, aunque, ciertamente, su actitud será totalmente distinta: "Biondo lo affronta con imbarazzo e fatica, come una difficoltà impostagli dal suo lavoro di storico, in contrasto con un dovere di eleganza formale che a tale lavoro è sentito como estrinseco" ${ }^{20}$. Así, mientras que para Biondo los neologismos son un mal menor, una dificultad añadida a la hora de escribir historia, una operación desagradable por tener que recurrir al vulgar para acuñar en latín nombres nuevos que ya tenían su nombre dado en ese vulgar, que ha de hacerse por pura necesidad, por tener que rebajarse a las ofertas de una lengua degenerada y diversa, en cambio, para Valla este operación le resulta agradable y se siente entusiasmado al contribuir así al enriquecimiento del latín a través del recambio permanente con elementos que provienen de la esfera del usus, de la consuetudo vigente, interna al latín mismo ${ }^{21}$.

NiCCOLO PEROTTI se inserta grosso modo en la línea renovadora de Valla, pero lo hace, sobre todo, desde el punto de vista conceptual, dado que en la práctica actúa con la misma precaución y reserva que Biondo. Ciertamente, Perotti, en la medida de lo posible, prefiere siempre "acondicionar" palabras conocidas a las nuevas realidades antes que utilizar creaciones reales:

Audendumque tamen censeo eruditis, et vocabula si non nova ponenda, derivanda saltem, flectenda, iungenda, ne sermonis paupertate laboremus, sed latina lingua in dies locupletior fiat. (PEROTTI, Cornu Copiae 2, 85$)^{22}$.

${ }^{19}$ Cf. BESOMI, Op. cit., p. 84 .

${ }^{20}$ M. TAVonI, "Lorenzo Valla e il volgare", p. 163, en O. BESOMI \& M. REgoliosI (eds.), Lorenzo Valla e l'Umanesimo italiano. Atti del Convegno internazionale di studi umanistici (Parma, 18-19 ottobre 1984), Padova, Editrice Antenore, pp. 199-216. Cf. también M. TAvoNI, Latino, grammatica, volgare. Storia di una questione umanistica (Medioevo e Umanesimo, 53), Padova, Editrice Antenore, 1984.

${ }^{21}$ Cf. M. Regoliosı, reseña a "M. Tavoni, Latino, grammatica, volgare. Storia di una questione umanistica, Padova, 1984" en Aevum, ${ }^{\circ}$ 59, pp.407-414.

${ }^{22}$ N. Perotti, Cormu Copiae, Jean-Louis Charlet \& Martine Furno (eds.), 4 vol., 1989-1995. 
Perotti ${ }^{23}$ no se muestra a favor de los neologismos reales, como 'equetarius' o 'bombarda', sino de los neologismos de sentido o incluso "de civilización", cuya presencia se justifica por su agradecida elegancia y utilidad. De hecho, en la Cornu Copiae esta categoría de neologismos de sentido está muy próxima a la de los vulgarismos (las palabras vernáculas que se introducen en el latín humanístico: verba peregrina), hasta el punto de que es imposible separarlos en el corpus léxico de Perotti, puesto que su actitud ante unos y otros es prácticamente similar. En su léxico, estas palabras sacadas de las lenguas vernáculas o que remiten a ellas, aparecen latinizadas y glosados por la expresión vulgo o vulgo nunc, es decir, están integradas en el latín y no fuera de él como sucedía en léxicos anteriores, en los que aparecían al lado de términos propiamente latinos con su ortografia vernácula. De esta manera, Perotti, en su afán pedagógico, que es su principal interés, logra dar mayor claridad a estos términos latinos, por lo general, técnicos y de difícil comprensión, al ofrecer un equivalente de la lengua común latinizado.

Por su parte, GIOVANNI PONTANO, frente al purismo moderado ajustado a las fuentes clásicas que muestra en el Actius, por lo que se refiere al léxico, en el De bello Neapolitano inserta numerosos neologismos y vulgarismos para señalar nombres de lugares, instituciones, instrumentos bélicos y militares, armas, cargos, etc., innovacines, que, sẹgún Liliana Monti, "lungi dal contraddire il purismo linguistico di principio, si giustificano da una parte con la necessità di far corrispondere a cose nuove termini di nuovo conio, immediantamente comprensibili al lettore contemporaneo, probabilmente in parte già presenti nel latino quattrocentesco, dall'altra con quel senso del latino letterario como lingua ancor viva e quidi suscettibile di nuove acquisizioni lessicali, che fu cosia spiccato e operante nel Pontano sia in prosa che in poesia ${ }^{24}$.

\section{NEBRIJA Y ESPAÑA.}

En España, fue, sin duda, Elio Antonio de Nebrija (1441-1522) el humanista que más se dedicó a las cuestiones relacionadas con el léxico. De entre sus muchas obras, cabe destacar el Dictionarium seu Lexicon ex sermone latino

${ }^{23}$ Cf. M. Furno, Le 'Cornu Copiae' de Niccolò Perotti. Culture et méthode d'un humaniste qui aimait les mots, Geneve, Librairie Droz S.A., 1995, pp. 137-146.

${ }^{24}$ L. Monti SABIA, Pontano e la Storia. Dal De bello Neapolitano all' Actius, Roma, Bulzoni Editore, 1985, pp. 32-33. 
in hispaniensem (Salamanca, 1492), el Dictionarium ex hispaniensi in latinum sermonem (Salamanca, 1495?), el Dictionarium Medicum y el Luris civilis lexicon. A éstas, habría que añadir una serie de trabajos "menores" donde se puede apreciar también su enorme interés por el léxico técnico e instrumental y por la definición de la terminología técnica presente en ellos como son las Introductiones Latinae $(1581)^{25}$, el capitulo titulado "De vocabulis quibus Cosmographi utuntur" que cierra el In cosmographiae libros introductorium (c. 1500) o los vocabularios que aparecen en algunas de sus Repetitiones, como la Repetitio sexta de mensuris o la Repetitio septima de ponderibus.

La cuestión que aquí nos ocupa, el neologismo, ha sido tratada por Gregorio $\mathrm{Hinojo}^{26}$ en algunas de sus publicaciones relativas a Nebrija. En ellas, podemos ver cómo son muchos los puntos de similitud entre Valla y Nebrija no sólo en sus ideas y actitud en materia filológica, cosa conocida, sino también en su situación personal. Ciertamente Elio, al poco de ser nombrado cronista regio, recibió el encargo de componer en latín unas Res Gestae de los Reyes Católicos. Al iniciar su empresa tuvo que hacer frente, como Valla, a la enorme dificultad que comportaba tener que escribir en latín sobre un mundo contemporáneo en el que existían nombres de lugares y personas desconocidos en la Antigüedad, numerosos conceptos y realidades nuevas, así como instituciones, armas, objetos, etc., y el grave problema de la ausencia de un rico léxico científico y técnico, como él mismo reconoce en las Décadas ${ }^{27}$ :

Et quamquam sunt multa quae mentis meae aciem perstringunt, nihil tamen est quod me magis a scribendo deterreat, quam locorum atque hominum propia nomina, quae maiori ex parte adeo sunt aspera et dura ut nullo cultu molliri, nulla diligentia possint mansuescere. Accessit altera non minor difficultas in nominandis Latine publicis magistratibus, cum in plerisque alia sit nostro tempore forma reipublicae.

${ }^{25}$ Cf. C. CODOÑER, "Las Introductiones Latinae de Nebrija: Tradición e innovación" en V. GARCiA DE LA CONCHA (Coord.), Academia literaria renacentista, Nebrija. Salamanca, Ediciones Universidad, 1983, pp. 105-132, especialmente pp. 119-120.

${ }^{26}$ Cf. G. HINOJO ANDRÉs, Obras históricas de Nebrija: estudio filológico, Salamanca, Ediciones Universidad, 1991; "La norma lingüistica en el latín renacentista" en Actas del VIII Congreso Español de Estudios Clásicos, 1994, Vol. 3, pp. 329-348; y "Nebrija y el desarrollo del léxico científico en latín" en Panace@, 2006, Vol. II, nº. 23. Junio (www.medtrad.org/panacea.html).

${ }^{27}$ E. A. NEBRIJA, Aelli Antonii Nebrisensis, ex grammatico et rhetore historiographi regii, rerum a Ferdinando et Elisabe Hispaniarum feliissimis regibus gestarum, Decades duae. Hispaniae Illustratae Scriptores, Francfort, 1603, p. 791. 
Esta preocupación de tener que traducir al latín todos estos nombres y, de manera especial, los nombres propios de personas y lugares, como se lee en el texto, le llevó a escribir una Excusatoria praefatio que por desgracia ha llegado hasta nuestros días de manera fragmentaria e incompleta.

En el plano teórico, Nebrija había establecido en el prefacio de su Dictionarium seu Lexicon ex sermone latino in hispaniensem de 1492 la siguiente clasificación de los vocablos latinos ${ }^{28}$ : Principio omnes dictiones in differentia esse quincuplici. Nam aut sunt oscae, aut priscae, aut novae, aut barbarae, aut probatae.

De los verba probata, palabras que podríamos denominar "habituales", además de distinguir entre las que usan los poetas, los oradores y los historiadores, especifica más adelante, incluso, el marco cronológico que abarcan ${ }^{29}:$ Probata vero vocabula sunt habenda, quibus auctores illi utuntur qui floruerunt intra ducentos circiter quinquaginta annos ab ortu Ciceronis ad Antoninum Pium.

Los verba barbara y los opica, es decir, barbarismos e vulgarismos, hay que emplearlos solamente si están avalados ya por algún autor y en pocas ocasiones, y hay que presentarlos con una glosa del tipo "ut ita dixerim, ut sic loquar" que excuse su impropiedad. Asimismo, los arcaísmos y los neologismos también hay que utilizarlos en escasas ocasiones y con discreción: los primeros, como testimonio de consideración de la Antigüedad y los segundos, por necesidad, cuando no existe en latín lo que queremos expresar.

Pero en la práctica, lo que realmente encontramos en las obras históricas de Nebrija es un acusado hibridismo entre su tendencia a mantener la tradición clásica, que le lleva a conservar, por ejemplo, la división administrativa romana de España en tres provincias o latinizar todos los nombres de personas, lugares, instituciones, cargos o magistraturas ${ }^{30}$, y su interés por acuñar y emplear neologismos para designar aquellas realidades que no encuentran

${ }^{28}$ E. A. NEBRIJA, Diccionario latino-español. Salamanca 1492. (Dictionarium seu Lexicon ex sermone latino in hispaniensem). Estudio Preliminar por G. COLÓN Y A.-J. Soberanas. Barcelona, Puvill-Editor, 1979, Prólogo, f. $5 \mathrm{a}_{\mathrm{iv}}$.

${ }^{29}$ Idem. Cf. E.A. NeBriJA, Prudentii opera cum commento A. Antonii Nebrissensi, in civitate Lucronii, Arnaldi Guilellmi de Brocario, 1512, p. 2.

${ }^{30} \mathrm{M}$. CONDE SALAZAR (edición y transcripción del texto latino, introducción, traducción y notas), Cerco al reino de Granada de Elio Antonio de Nebrija, Madrid, UNED, 1992, p. 12. 
correspondencia con la terminología latina clásica. Ciertamente, no podemos valorar en su justa medida cuál de las dos actitudes tiene más peso, dado que no hemos realizado un estudio minucioso de las obras históricas de Nebrija. Pero sí podemos afirmar a partir de varios párrafos de la Excusatoria praefatio que, según Nebrija, la terminología clásica no vale para todo, que las barbarae appellationes se evitarán, sólo cuando sea posible y que cuando sea necesario habrá que crear neologismos ${ }^{31}$ :

Quare et nos non omnia dabimus antiquitati, sed neque semper incertum vulgus sequemur fugiemus tamen, quoad fieri poterit, babaras appellationes, sequemurque voces sermoni latino usitatas, etiamsi tantumdem non valeant.

... apud antiquiores aliae fuerunt rerumpublicarum formae quam sint nostro saeculo [y por tanto] nomina fingenda sunt...

... sunt etiam vocabula, quibus nihil in altera gubernatione respondet, ut ei, qui est Dictator sive Censor apud Romanos, nihil respondet apud nos, et ei, id est apud nos Marques aut Almirante, nihil respondet apud Romanos. Quare in huiusmodi rebus norma fingenda sunt, ut illum appellemus Marchionem quasi a Marcha, hunc classicae praefectum $^{32}$, aut si te magis Graece delectant Navarchum sive Architalassum dicere licebit. Nam Archimarinus, quo aliqui utuntur, neque graece neque latine diceretur, cum nullum sit nomen, quod ex duobus peregrans componatur...

Por último, hay que señalar que Gregorio Hinojo ha insistido en varios artículos en la idea de que Nebrija contribuyó considerablemente al enriquecimiento de la lengua latina de su época en el plano léxico, sobre todo, en lo que atañe al léxico técnico y científico. Esta copia dicendi la consiguió mediante tres procedimientos principales:

\section{1.- CANON DE AUTORES}

Frente a la postura de muchos humanistas ortodoxos que consideraron que los únicos autores válidos como modelos eran los que habían escrito

${ }^{31}$ Los tres textos pertenecen a la Excusatoria praefatio de Aelli Antonii Nebrisensis, ex grammatico et rhetore historiographi regii, rerum a Ferdinando et Elisabe Hispaniarum feliissimis regibus gestarum, Decades. Cf. para los dos primeros G. HINOJO ANDRÉs, "Nebrija y la traducción de términos históricos e institucionales", p. 470, en J. A. BARTOL HERnÁNDEZ, J. DE SANTIAGo Guervós, J. F. Garcia SANTOS (COORD.): Estudios filológicos en homenaje a Eugenio de Bustos Tovar, Salamanca, Ediciones de la Universidad de Salamanca, Vol. 1, pp. 469-477; para el último, CONDE SALAZAR, Op. cit., p. 12.

${ }^{32}$ Cf. VAlla, GF 132 (II 13, 20); 128 (II 13, 1). 
durante la época clásica, Nebrija incrementó el canon, estableciendo el siguiente criterio $^{33}$ :

Iudicium meum semper fuit synceri atque puri sermonis eos tantum fuisse autores qui floruerunt intra ducentos annos qui sunt ab aetate Ciceronis ad Antoninum pium, et ad phrasim eloquentiae faciendam hos tantum esse proponendos imitandosque. Ceteros vero quia plurimum conducunt ad multarum rerum cognitionem, non esse contemnendos atque in primis christianos qui nos ad religionem erudiunt, et magna ex parte facundiam augent.

Así pues, en sus obras, encontramos términos que van desde Plauto hasta Casiodoro e Isidoro, pasando por Prisciano, Varrón, Gelio, Vitrubio, Columela, Galeno, Celso, Frontino, etc., sin olvidar la Biblia y los autores cristianos ${ }^{34}$. Ciertamente, los modelos literarios y los maestros del estilo siguen siendo los clásicos, pero de todos los demás se puede aprovechar el léxico o los temas y, de manera especial, de los cristianos.

\section{2.- CAMBIO Y AMPLIACIÓN DEL SIGNIFICADO}

Este procedimiento consiste básicamente en la adaptación de términos latinos antiguos a las exigencias comunicativas de la época, de manera que las palabras viejas adquieren nuevos significados modificando, ampliando o especializando el sentido que anteriormente tenían. En este grupo entran los conocidos ejemplos de 'dux', 'princeps', 'comes', 'magister' y otros más propios de Nebrija como 'vivarium' que de "vivero, pecera, reserva de animales de caza" pasó a utilizarse con el valor de "soldados cercados sin posibilidad de salvación" o 'cavilla' que en Plauto significaba "chanza" y en Nebrija "engaño perverso, malicia" 35 . En ocasiones, estos nuevos significados se ayudan de una glosa, una aclaración, una definición o es el propio contexto el que nos proporciona su significado.

${ }^{33}$ Nebrija, Op. cit., 1512, p. 2. En consonancia con este criterio están las palabras de J. L. VIVES, De causis corruptarum artium (Über die Gründe des Verfalls der Künste). Edición, comentario, introducción, bibliografia e indices de E. HIDALGO-SERNA, traducción al alemán de W. SENDNER con la colaboración de C. WOLF y E. Hidalgo-Serna. Manchen, Fink, 1990, p. 176: Quid in iis faciemus, de quibus [Cicero] non est locutus? Ut de aedificiis, de agro colendo, de rustico aut barbaro aut bellico instrumento. Num tacendum erit?

${ }^{34}$ Cf. Hinoso, Op. cit., 2006, p. 124.

${ }^{35}$ Cf. Hinojo, Op. cit., 2006, p. 125. 


\section{3.- FORMACIÓN DE NEOLOGISMOS}

Como ya se ha advertido en muchas ocasiones, Nebrija puede considerarse con toda justicia un fiel seguidor de Valla en materia lingüística y en el caso del neologismo el paralelismo es más que evidente. En varios pasajes de sus obras insiste en la necesidad de formar neologismos que incrementen el caudal léxico latino y su capacidad de expresión. Este interés por el neologismo casa perfectamente con su concepción del latín como lengua «viva». Estos neologismos han de ser creados y propuestos por "probatissimi auctores" $\mathrm{y}$ avalados por el "doctissimorum virorum usu" palabras que él mismo crea, de las que dice que han de utilizarse hasta que estos auctores inventen otras mejores ${ }^{37}$ :

Nova (vocabula) sunt quae probatissimi auctores ausi sunt in medium proferre cum antea non essent... Sic nostra aetate Franciscus Philelphus 'stapeda', pro eo quod hispane dicitur 'estribo ${ }^{38}$. Cuius audacia quamquam est a plaerisque reclamatum, potest tamen excusari, quod nullum invenit latinum nomen quo posset significare id quod volebat, cum neque res ipsa fuerit apud antiquos. Sic et nos ipsi multa in hoc genere sumus ausi, quibus ego interim censeo utendum, quod meliora ab aliis fuerint inventa.

Como veíamos en algunos de los textos anteriores, sólo en el caso de que no exista un nombre latino que pueda designar la nueva realidad hay que recurrir al neologismo.

En conclusión, podemos afirmar que Nebrija mantuvo con relación a los nova verba una postura prudente y ecléctica empleando, cuando la necesidad lo imponía, neologismos o verba peregrina para designar las nuevas realidades que no tenían correspondencia en la terminología latina clásica. Así, lejos de ser un servil imitador de la terminología historiográfica latina clásica y de latinazar absolutamente todo ${ }^{39}$, Nebrija, perfecto conocedor de la gramática y consumado lexicógrafo ${ }^{40}$, se sitúa en la línea innovadora iniciada por los humanistas italianos Biondo Flavio y Lorenzo Valla, al que sigue muy de cerca en

${ }^{36}$ Cf. VALLA, GF 194 (Appendice III 1).

${ }^{37}$ Nebrija, Op. cit., 1979, Prólogo, f. 4, $\mathrm{r}_{\mathrm{v}}$.

${ }^{38}$ Cf. VALLA, GF 199 (Appendice III 14).

${ }^{39}$ Cf. Hinojo, Op. cit., 1992, p. 471.

${ }^{40}$ Ciertamente, Nebrija compuso sus obras historiográficas al final de su vida, dejando algunas inconclusas al sobrevenirle la muerte, cuando ya poseía un vasto conocimiento en materia léxica y de tradición clásica. 
muchos de sus postulados como hemos podido comprobar y cuyos ecos resuenan en muchos de sus textos ${ }^{4 !}$.

Junto a Nebrija podemos citar, en España, a otros humanistas que al escribir sus obras historiográficas se encontraron con los mismos problemas y que optaron por idénticas soluciones, es decir, compaginar la terminología clásica, adaptando, a veces, el significado de algunos vocablos a las nuevas realidades con la creación de neologismos. Entre estos historiadores podemos citar a Juan Maldonado (1485-1554) y su historia sobre el levantamiento de las Comunidades de Castilla: el De Motu Hispaniae de $1525^{42}$; a Juan Ginés de Sepúlveda ${ }^{43}(1490-1573)$ y su historia sobre la conquista del Nuevo Mundo: el De orbe novo; y a Juan de Verzosa (1522-1574) y sus Anales del reinado de Felipe $I^{44}$. p. 791 .

${ }^{41}$ Por ejemplo, en las Décadas a propósito de 'bombarda' Cf. NeBriJa, Op. cit., 1603,

${ }^{42}$ M. Martinez Quintana "El léxico de las instituciones en el De Motu Hispaniae de Juan de Maldonado: procedimientos de latinización" en Actas del VIII Congreso Español de Estudios Clásicos (Madrid, 23 al 28 de septiembre de 1991), Madrid, Ediciones Clásicas, 1994, pp. 499-504.

${ }^{43}$ Cf. L. Rivero Garcia, El latin del De Orbe Novo de Juan Ginés de Sepúlveda, Salamanca, 1993, especialmente pp. 66-173; y "La prosa latina humanística y el problema del léxico a través de la crónica indiana de Juan Ginés de Sepúlveda" en J. M². MAESTRE Y J. Pascual Barea (COORD.), Humanismo y pervivencia del Mundo Clásico. Actas del I Simposio sobre Humanismo y pervivencia del Mundo Clásico, Cádiz-Instituto de Estudios Turolenses, 1993, Volumen I, pp. 917-929.

44 JUAN DE VERZOSA, Anales del reinado de Felipe II. Introducción, edición crítica, traducción anotada e índices a cargo de J. M. MAESTRE, Madrid-Alcañiz: Instituto de Estudios Humanísticos, 2002, especialmente pp. 122-132. 